\title{
Cross Wedge Rolling ANd Forging Rolls as AdDitional DEVICES IN ClOSED DIE FORGING
}

\author{
Martin Zahálka, Jiř́i Staněk, Karel Ráž \\ University of West Bohemia, Faculty of Mechanical Engineering, Department of Machine Design, Univerzitni 22, \\ Pilsen 306 14, Czech Republic
}

\begin{abstract}
The article deals with the possibility of additional devices in closed die forging technology using mechanical presses. The main purpose of the additional equipment should be increasing of the productivity.

Way to increase productivity may be appropriate connection of the press with a device for material preforming. The article presents ways of preforming with usage of forging rolls and cross wedge rolling.

The output is a comparison of both methods on the example of preform and evaluation of the advantages and disadvantages of the individual methods. Both methods of preforming are analyzed using finite element method simulations.
\end{abstract}

Keywords: forging rolls; cross wedge rolling; preforming
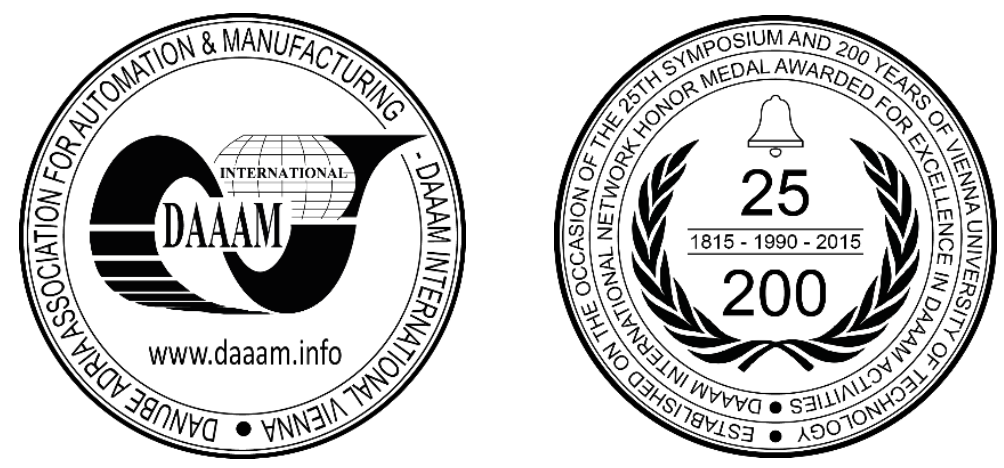

This Publication has to be referred as: Zahalka, M[artin]; Stanek, J[iri] \& Raz, K[arel] (2016). Cross Wedge Rolling and Forging Rolls as Additional Devices in Closed Die Forging, Proceedings of the 26th DAAAM International Symposium, pp.0530-0535, B. Katalinic (Ed.), Published by DAAAM International, ISBN 978-3-902734-07-5, ISSN 1726-9679, Vienna, Austria

DOI: $10.2507 / 26$ th.daaam.proceedings.072 


\section{Introduction}

In all areas of industry, great accent is on productivity and quality in all processes that are highly repetitive. It means processes in serial and mass production. This problem has to be solved also by forging factories.

Products of these factories are mainly forged components for the automotive industry.

In automated lines is the weakest member forging press. Press is chosen by the size and shape of forged part. Size, material and technological parameters affect the required force of forging press. The difficulty of the part affects the number of strokes needed for correct forging of the parts and also affects the size of the working space of the press.

Productivity of whole forging line is determined by the number of pieces that is the press able to produce per unit of time. Increasing of strokes number leads to decreasing of productivity.

Productivity can be increased by using several series-connected presses, which cost considerable investment resources, or reduce the number of strokes needed to forge parts. Usually higher frequency of strokes is not possible with regard to the technical possibilities of the press, or the time required for handling with parts.

The University of West Bohemia in cooperation with company Smeral Brno a.s. deals with the development of the preforming machines, mainly forging rolls for several years for these reasons. These additional devices significantly improve their competitiveness of manufactured presses. [8]

\section{Possibilities of productivity increasing}

\subsection{State with one press}

All strikes to the final forging are performed in the progressive die of the press. For the selected case forging of connecting rod must be done by using four operations.
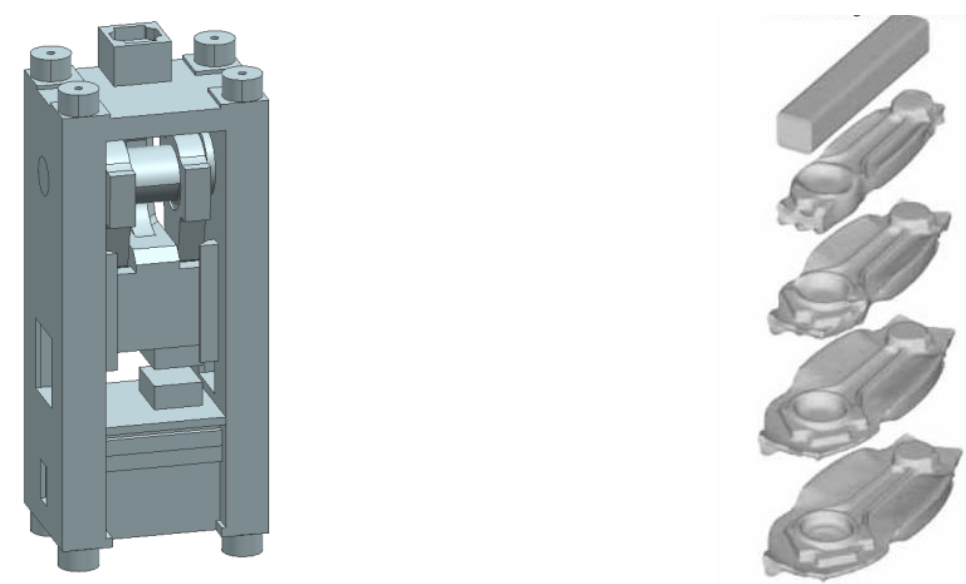

Fig. 1. Press with representation of individual strokes after forging

\subsection{Using of series-connected presses}

To increase productivity, we can use two presses, which will gradually forge every two strokes. The productivity is twice higher in this case. It is also possible to use presses with smaller working area, which are cheaper.

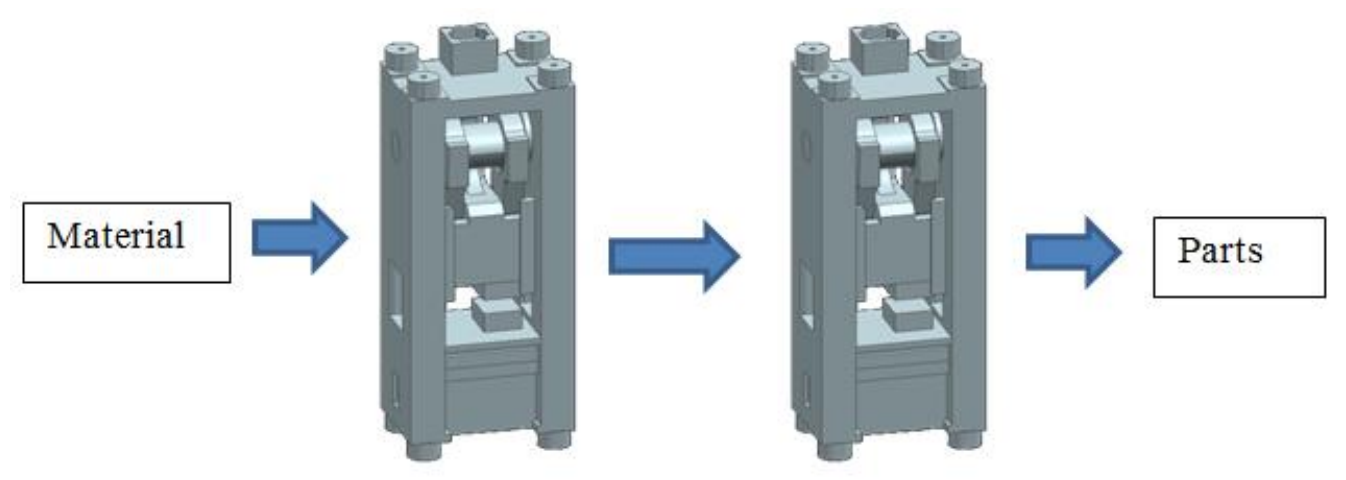

Fig. 2. Series-connected presses 


\subsection{Using of parallel presses}

The same productivity can be reached with two parallel presses, where everyone will perform four strokes. In this case we have to keep the same size presses with the original one.

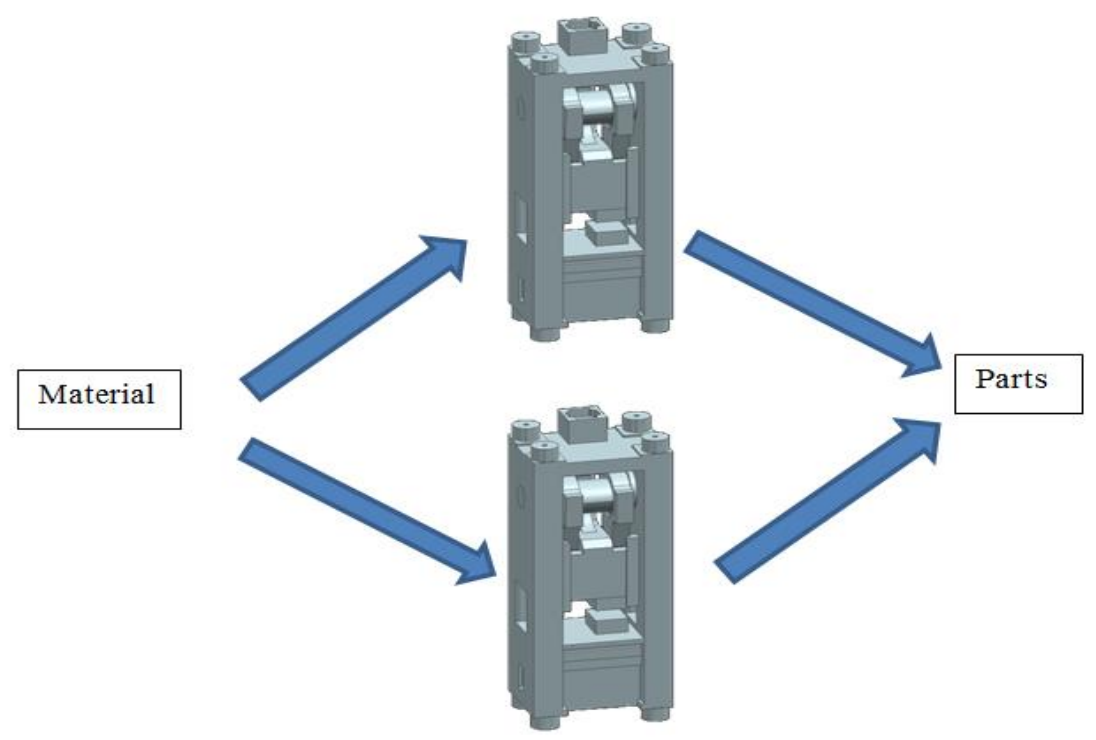

Fig. 3. Parallel presses

\subsection{Using of additional devices}

Because usage of another press leads to considerable costs and reduce the number of strokes is this not possible from the technological point of view. These problems can be solved by using an alternative device to transfer or replacement some strokes of the press forming on another machine. in this case.

The shaping of the material, in the first cavities 1 and 2, see Figure 1 or 4, may be performed in another device

Thanks to this step can be realized operations in which part gets the final shape only on the press. The result is a smaller and cheaper press with higher productivity.

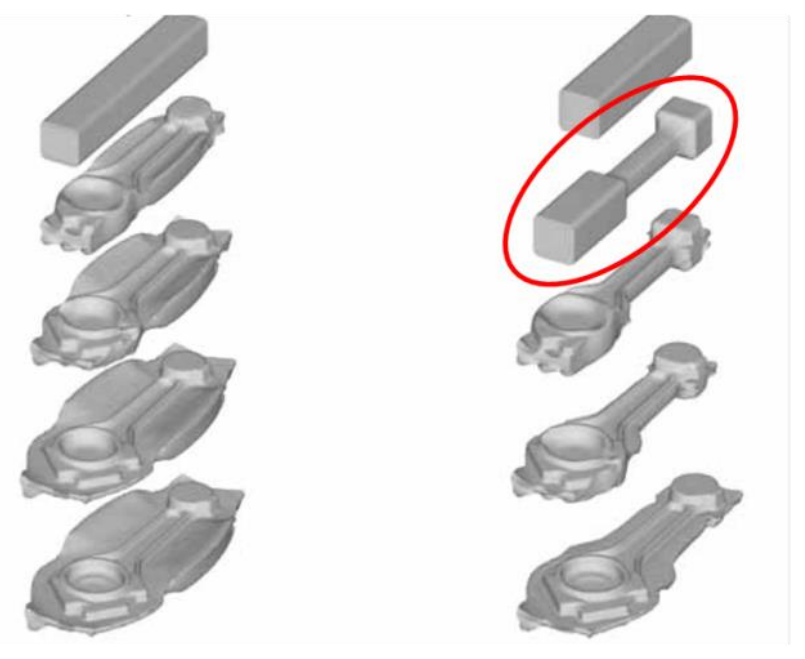

Fig. 4. Comparison of the forging by closed die and forging rolls

\section{Technological equipment for preforming}

Purpose of the material preforming is redistribution of material before inserting it into the tool (die) of forging press. By selecting a suitable method of preforming is possible to achieve important material savings and reducing of power and energy of the press.

In the following chapters will be description of two most useful ways of material preforming - cross wedge rolling and forging rolls. 


\subsection{Forging rolls}

Forming is done in several passages between forging rolls. In this type of preforming bar is possible to achieve non-circular shape of the forgings. This depends on the shape of rolls $[2,6,7]$.

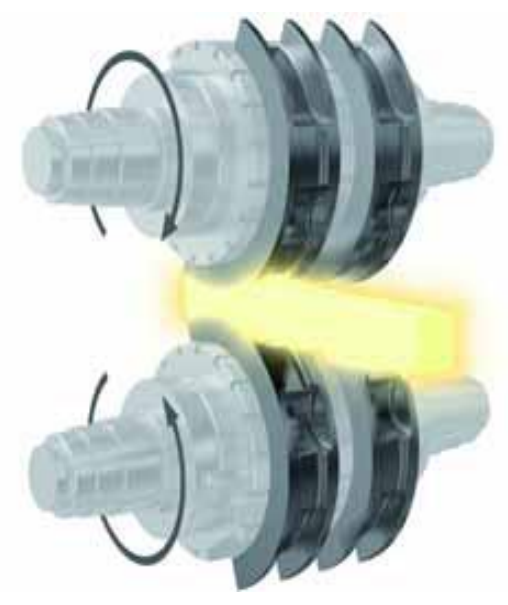

Fig. 5. Forging rolls

\subsection{Cross wedge rolling}

Because this is a technology where the material rotates between the rotating tools, the resulting product is always rotational. $[1,4]$

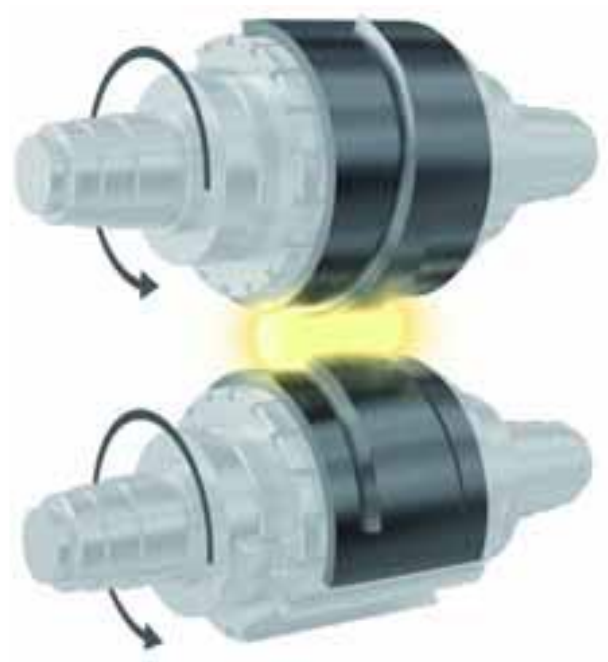

Fig. 6. Cross wedge rolling

\section{Comparison of forging rolls and cross wedge rolling by using virtual simulation}

Both methods are used primarily for preforming of the material, in many cases it is possible to use both methods with comparable results. In order to facilitate the selection of the right technology will be done comparing of both methods.

Comparing consists of creating an identical part by forging rolls and cross wedge rolling. These parameters of comparison will be parameters of technological operations (power, energy ...) and machine parameters (productivity achieved accuracy ...).

\subsection{The choice of part shape}

The selected piece of material is used for forging of connecting rod, which is shown in the following figure. mirroring.

In order uniform distribution of the forces along the forging, these kinds of parts are forged in pairs with 
To achieve of connecting rod is determined the following optimum shape of preform, so that it can be achieved by cross wedge rolling and forging rolls. [3]
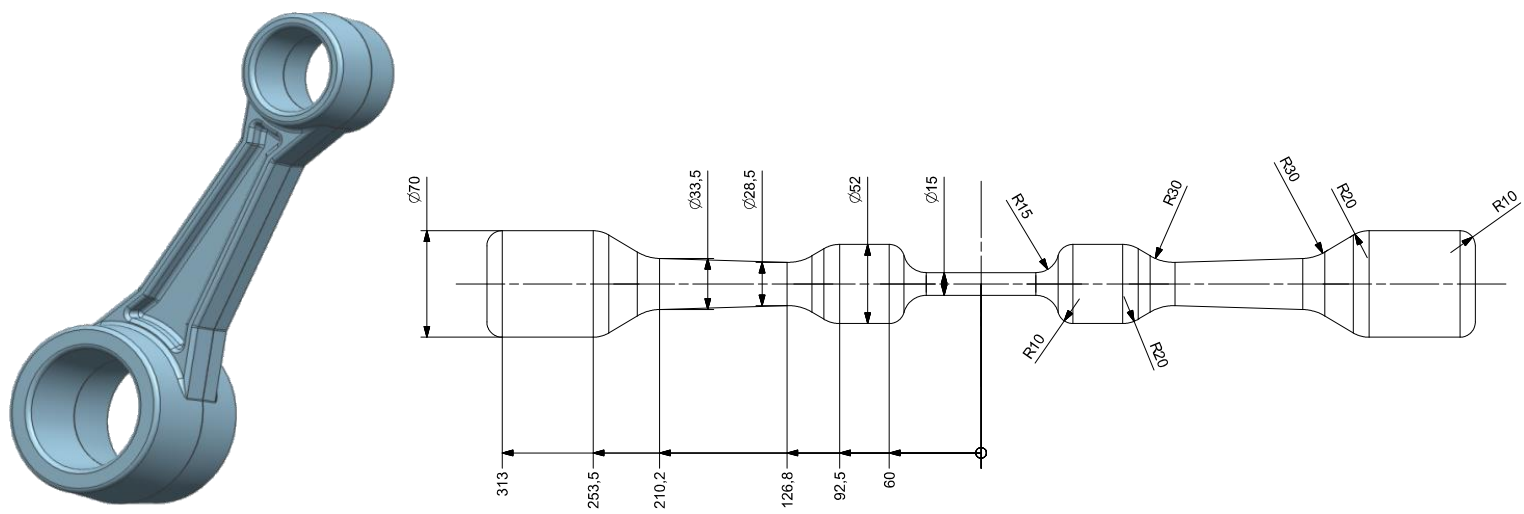

Fig. 7. Connecting rod and optimum shape of preform

\subsection{Forming simulation}

Simulation parameters of forming technology:

- $\quad$ Material DIN 12060 (AISI 1055)

- Temperature $1100^{\circ} \mathrm{C}$

- Weight $8 \mathrm{~kg}$

- Input preform rod 70x300mm

- Revolutions of forging rolls $0.5 \mathrm{rev} / \mathrm{sec}$.

- Revolutions of tool cross wedge rolling $0.5 \mathrm{rev} / \mathrm{sec}$.

From both simulations were obtained radial forces and torques of the drive. Progresses of these variables will be compared later.

\subsection{Cross wedge rolling simulation}

The forming simulation using cross wedge rolling is shown in the following figures. This simulations was done by DEFORM 3D program. The graph shows the force and torque depending on time of forming.
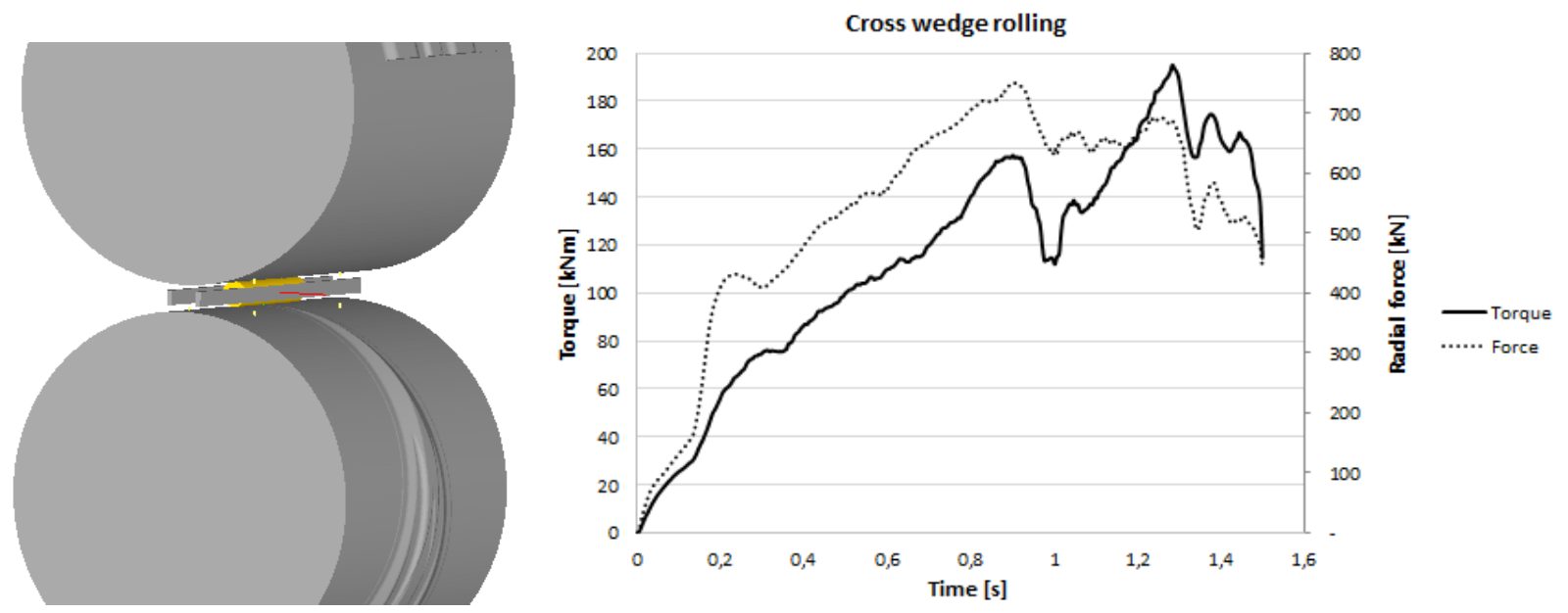

Fig. 8. Cross wedge rolling simulation and the progress of radial force and torque of cross wedge rolling

\subsection{Forging rolls simulation}

Forming using forging rolls cannot be done in one pass as in the cross wedge rolling. In this case, 6 passes are required. The forming simulation is presented for the last, sixth passage, which reaches the greatest force and torque values. The graph from DEFORM 3D shows the force and torque depending on time of forming 

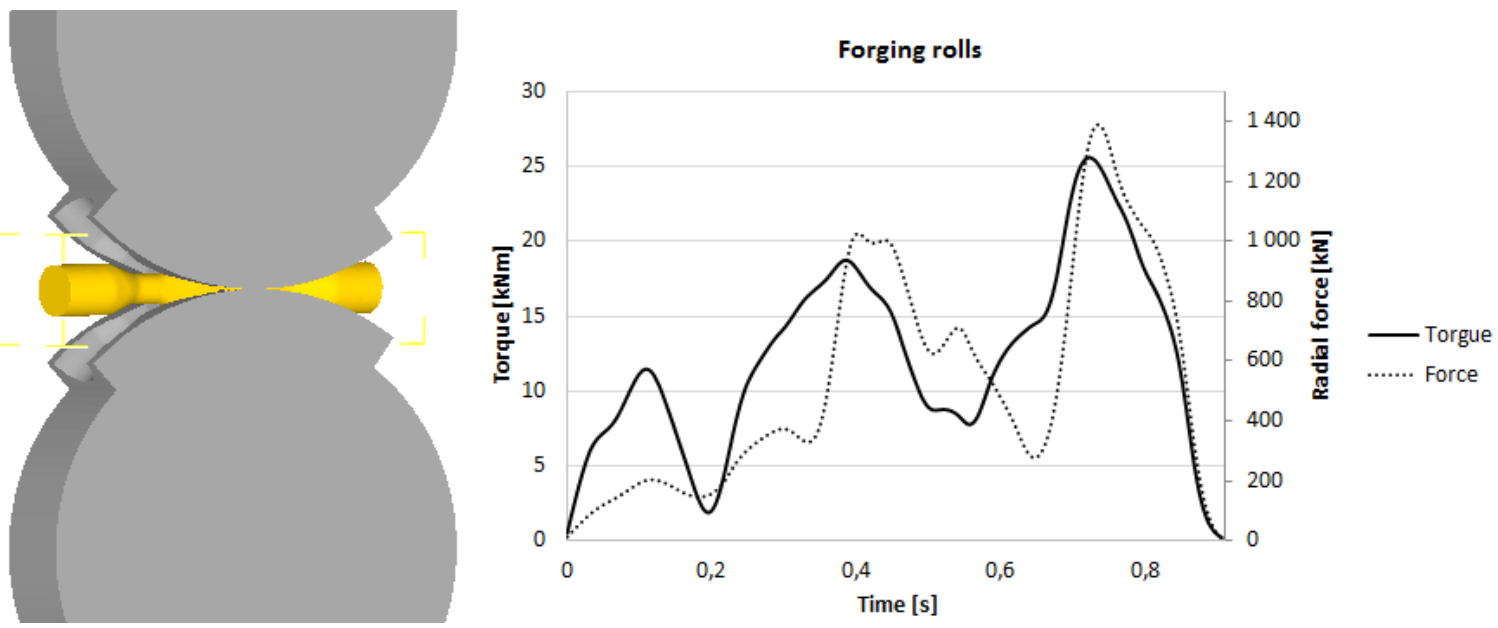

Fig. 9. Forging rolls simulation and the course of radial force and torque of forging rolls

\section{Conclusion}

The following table is a summary of measured values for both simulations. It is obvious that in forging rolls technology is reached about twice the force in comparison with cross wedge rolling, the other hand reached torque is only $1 / 8$.

\begin{tabular}{cccc}
\hline & $\begin{array}{c}\text { Radial force } \\
{[\mathrm{MN}]}\end{array}$ & $\begin{array}{c}\text { Torque } \\
{[\mathrm{kNm}]}\end{array}$ & Time $[\mathrm{s}]$ \\
\hline Forging rolls & 1,41 & 25,7 & 1.1 \\
$\begin{array}{c}\text { Cross wedge } \\
\text { rolling }\end{array}$ & 0,77 & 202 & 1.5 \\
\hline
\end{tabular}

Table 1. The parameter comparison

From the viewpoint of energy intensity is not suitable to choose cross wedge rolling, but forging rolls energy shows the value for one pass. If it is considered 4-6 passages, the difference is not so extreme.

If productivity is compared, cross wedge rolling is definitely more suitable. If we consider the maximum press frequency 20 strokes per minute with the three dies, one forged part needs 9 seconds. The same productivity must have preforming device. This limit is easily achievable by cross wedge rolling. However, for forging rolls, which would need 4 to 5 passages it is hardly performable without quick automation.

It can be said that for forgings are sufficient both ways of forming. If the required shape of the preform was different (non-circular) could be used only forging rolls. On the other hand, if is requested high precision is better to use cross-wedge rolling.

\section{Acknowledgements}

The paper was supported by the "Regionalni technologicky institut" reg. no. CZ.1.05/2.1.00/03.0093.

\section{References}

[1] LASCO. Cross-Wedge and Forging Rolls. Coburg, Germany : LASCO Umformtechnik.

[2] Ajax. Wide adjustement forging rolls. CLeveland, Ohio : The Ajax manufacturing Co.

[3] Karacaovali, H. Analysis of roll-forging process. Ankara, Turkey, 2005.

[4] Holub, Jiř́: Cross wedge rolling, 1., Praha: 1972

[5] Piscan, I., Janssens, T., Predincea, N. Experimental Validation of FEM for frictional Contacts.Annals of DAAAM for 2011, Vienna, 2011, 741-742

[6] Manyo Co., Ltd. Forging rolls. Manyo. [Online: 24. 3 2014.] http://www.manyo.com/product/fr.html

[7] Inc., BW Walden Group. EUMUCO - FORGING ROLL. Details for Category: FORGING ROLL. [Online: 24. 3 2014.] http://www.bwgroupinc.com/EquipDetail.aspx?EquipGUID=1 cbdd4bb-bd0e-4f49-b838-410205d20d88

[8] Company literature of Smeral Brno a.s. 